\title{
Corrigendum
}

\section{Corrigendum to "Use of Aripiprazole Long Acting Injection in Negative Symptoms of Schizophrenia"}

\author{
Suneeta James, Chaya Kapugama, and Mohammed Al-Uzri \\ Leicestershire Partnership NHS Trust, Bradgate Mental Health Unit, Groby Road, Leicester, Leicestershire LE3 9EJ, UK \\ Correspondence should be addressed to Suneeta James; suneetajames@hotmail.com \\ Received 17 June 2019; Accepted 19 June 2019; Published 16 September 2019 \\ Copyright (C) 2019 Suneeta James et al. This is an open access article distributed under the Creative Commons Attribution License, \\ which permits unrestricted use, distribution, and reproduction in any medium, provided the original work is properly cited.
}

In the article titled "Use of Aripiprazole Long Acting Injection in Negative Symptoms of Schizophrenia" [1], there was an error in the Abstract as the patient was mistakenly described to be of "Afro-Caribbean origin" and once again as an "AfroCaribbean female" in the "2. Case Presentation" section. The authors apologize for that mistake as the patient should be referred to as "a female of African descent" instead.

\section{References}

[1] S. James, C. Kapugama, and M. Al-Uzri, "Use of aripiprazole long acting injection in negative symptoms of schizophrenia," Case Reports in Psychiatry, vol. 2016, Article ID 7912083, 3 pages, 2016. 


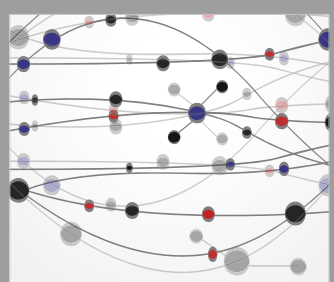

The Scientific World Journal
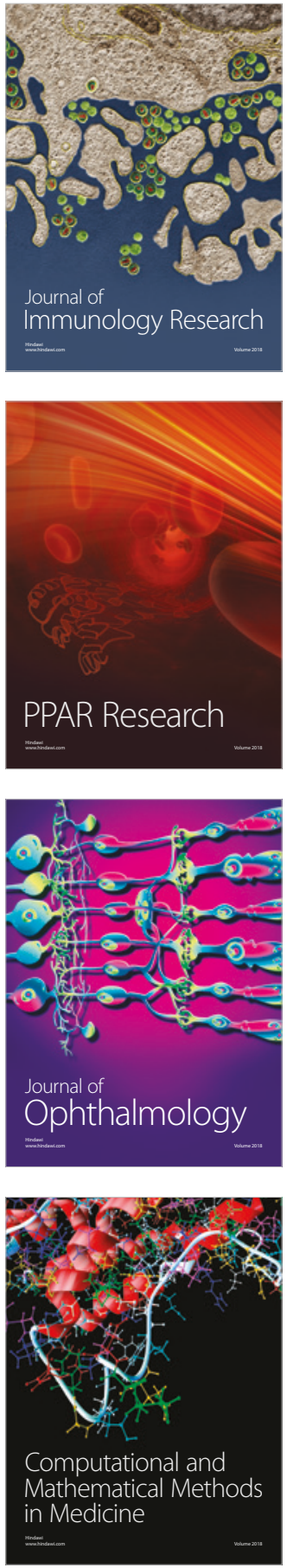

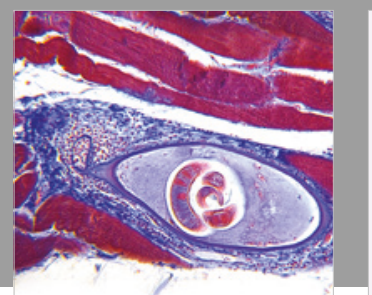

Gastroenterology Research and Practice

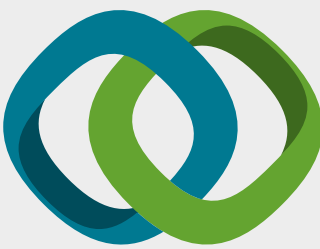

\section{Hindawi}

Submit your manuscripts at

www.hindawi.com
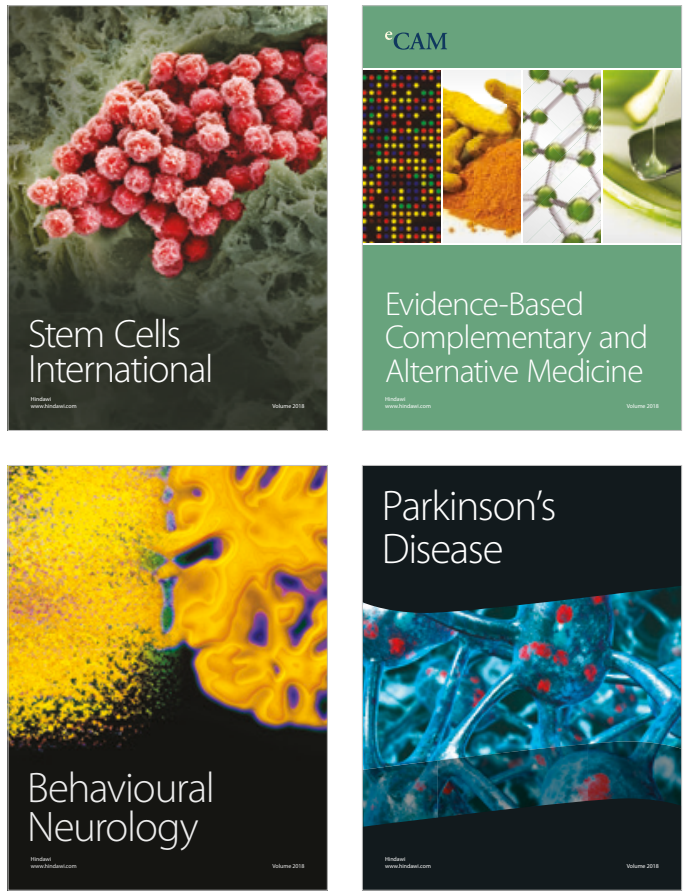

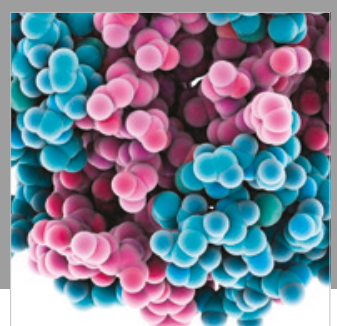

ournal of

Diabetes Research

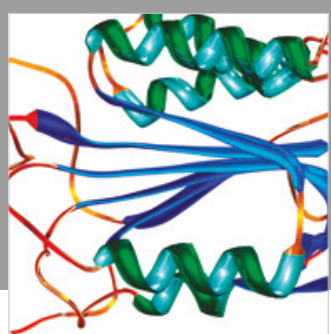

Disease Markers
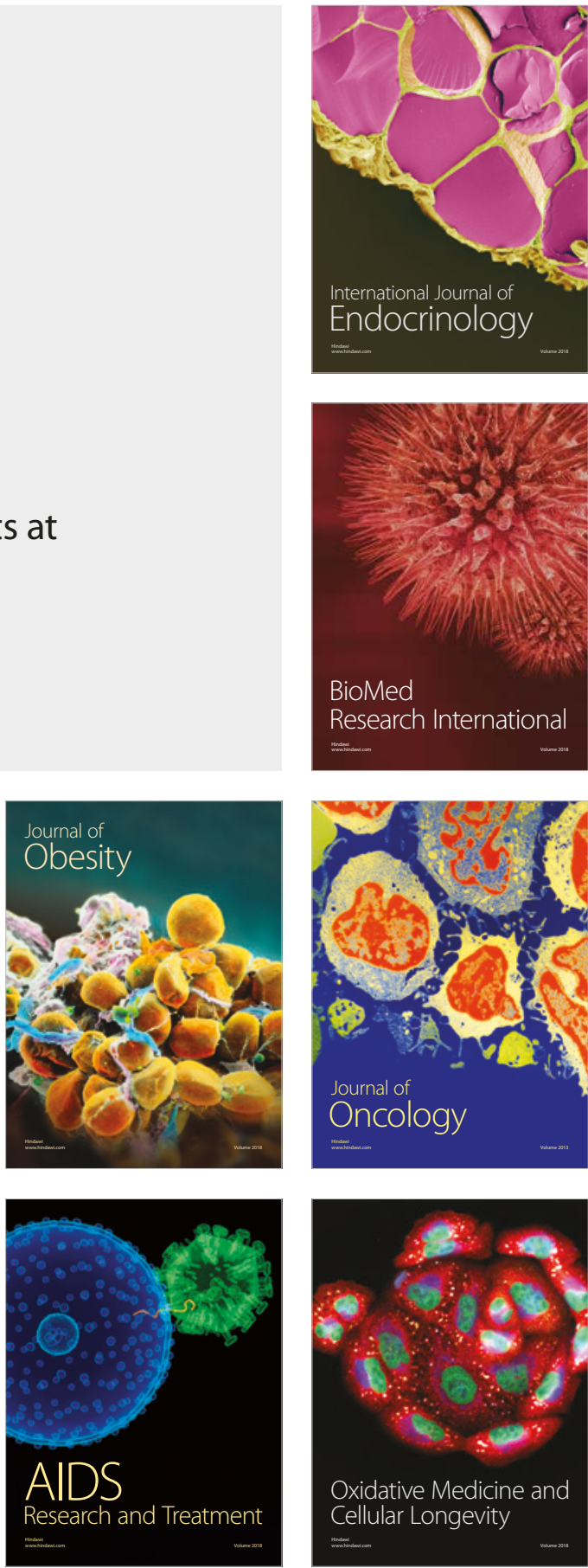